\title{
Architectural Design of Trust Based Recommendation System in Customer Relationship Management
}

\author{
Mohammed Yassine El Ghoumari ${ }^{1}$, Abderrahmane Daif ${ }^{2}$, Reda Moulouki ${ }^{2}$, \\ Houda Jihal ${ }^{2}$, MohamedAzzouazi ${ }^{2}$ \\ ${ }^{1}$ National School of Business and Management ENCG, Hassan II University, Casablanca \\ ${ }^{2}$ Departement of Mathematics and Computer Science, Hassan II University, Casablanca
}

\section{Article Info}

Received Jun 18, 2018

\section{Keyword:}

CRM, Big Data, e-CRM, Recommendation, Trust, Model

\begin{abstract}
Most Companies are more customer centric than they were before. By adopting this strategy, it made the electronic commerce growing and enhance buyers experience. from the other side, Companies started to explore this customer experience -data generated- to extract knowledge about their customer to be well managed - eCRM - instead of classic customer relationship Management - CRM. Large quantity of Data motivated the companies to look for changes, and ask for more functionality, and this are what influenced software editors to adapt their solutions and implement the power of data. Nowadays, data available - Big Data - put the existing systems and architectures under question and push us to rethink the logical layer to explore this data. Following the data vague, puts a need to reconsider and study the strength of eCRM/CRM existing solutions and architectures.

The main contribution of this paper is to propose architecture built on Trust-Based recommendation able to provide to companies better accuracy, coverage, novelty and diversity during the sales process.
\end{abstract}

\section{Corresponding Author:}

Mohammed Yassine El Ghoumari,

National School of Business and Management ENCG,

Hassan II University, Casablanca

2725 Route des Chaux et Ciments, 20250 Casablanca.

Email: yassine.elghoumari@univh2c.ma 


\section{Introduction}

Customer relationship management (CRM) refers to the entire IT system dedicated to customer relationship management. CRM is then the IT solution to manage all information about customers and prospects and all interactions with them.

Easy access to information has definitely changed the nature of customers by making them more and more demanding, so another reflection is needed on the customer relationship.[18]

New technologies and knowledge that we can get from data available on social networks [16], can be a new opportunity that will enhance customer management strategies, to avoid customer retention and be aware about competition benefits.

This Data knowledge can help also active departments within a company specially sales, to well define targets and have clear vision of its current and future customers.

The implementation of CRM in companies requires several challenges, in fact about $70 \%$ of CRM projects lead to either losses or no improvement in the performance of the company according to market research commercial [Web-1]. These negative results are well described at the academic and professional level [2]. That's why many companies and startups focused on the big-data [14] and CRM business niche have been forced to revise their architecture because of the diversity and heterogeneity of the data available.

To improve the performance of CRM, we propose in this article a trust-based recommendation architecture, which will include a big data module. Trust-based recommendation offers big potential to avoid CRM limitations. This allows users to know who and how much to trust each other by evaluating the quality of the ranking information they receive.

This document is organized as follows: in the second section, current architectures will be discussed, in section 3, we will define new model of architecture that is adapted to big data then in section 4 conclusion and other research path will be presented.

\section{CRM PRINCIPLES ANDARCHITECTURE:}

\subsection{DEFINITIONS}

\section{CRM:}

Customer Relationship Management is a set of tools and techniques that :

- Collecting and populating Data of a customer

- Respond to customer complaints and needs in a fast and convenient SLA

- store a record of customer information

- Re-use this information and learn to understand the needs of the customer

Customer Relationship Management (CRM) is a process companies use to understand their customer groups and respond quickly - and at times, instantly - to shifting customer desires, CRM technology allows firms to collect and manage large amounts of customer data and then carry out strategies based on that information.

\section{$\underline{\text { Social CRM }}$}

Social customer relationship management (social CRM) refers to the use of social media and social media techniques to engage a business's customer base, Social CRM is seen as a customer-centric approach to providing service and product support. And reply generally to how to incorporate customer 
relationship management (CRM) analytics into your social media marketing strategy to grow the online presence and the business $[10,19]$.

\subsection{CRM ARCHITECTURES}

Similiraties can be shown and presented from the Studies of CRM architectures in [5], [6] and [8]. Figure 1 shows the CRM conceptual components:

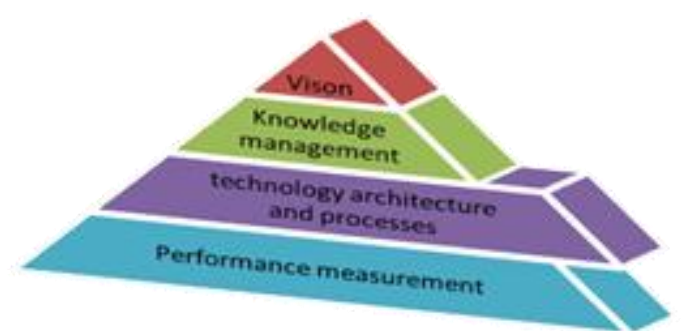

Figure 1. CRM Components

Business process and technology model present an important fragment of CRM system. According to HP and Gartner [7] we can define three technology classes:

Collaborative technology:

Due to developed communication technologies that participate on collaborative technology let customer network with organizations. According to [22] this is centralized communication network that can include the entire supply chain [11).

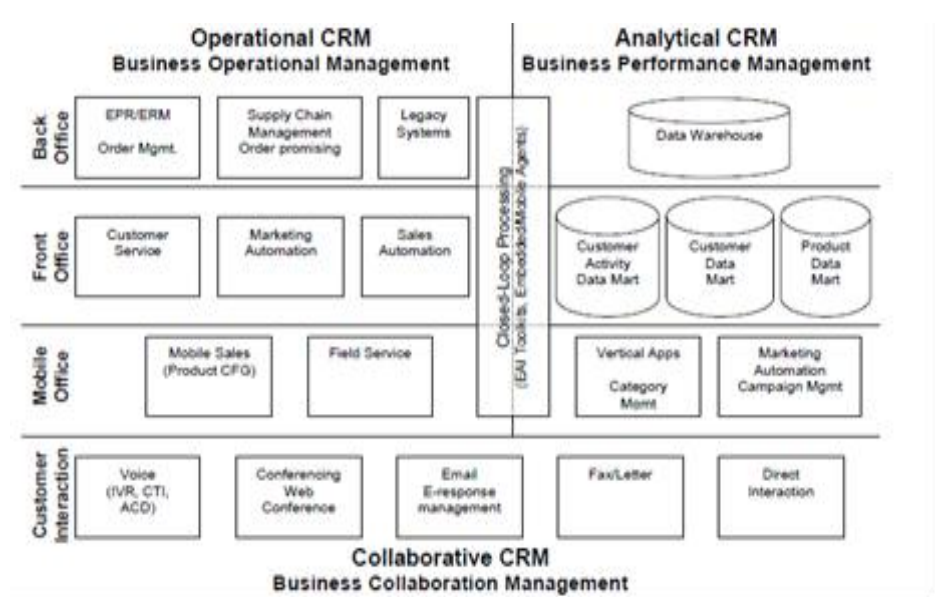

Technology class present the main class that participated of eCRM system enhancement, which is based on Web, this facilitated the way and give more communication channel (extranet, intranet, and mobile) [12]

New available Data due to Big Data wave, push solution editors to adapt them in order to have new features that aims to exchange data with new channels, and explore different types of non-structured data.

Operational Technology:

Main function consists of integration and automation of horizontal process in association with the customer - front-office and back-office. they ensure the constant improvement of the sales, marketing and customer service processes and enable to automate and manage:

- Managing contact and track the leads, and opportunities that represent Marketing Plan.

- channels and sources

- Sales forces (registration of visits and surveys, marking potential customers) 
- Folowing sales Agent (sales forces) actions (visits, potential customers, and surveys)

Among operational CRM important component, is Call Center, [22], this allow the companies to store recorded calls and collect the information needed to follow the customer story with the company [22].

\section{Analytical Technology:}

We group the applications used to analyze the data collected in operational CRM applications (Customer Relationship Management). The Analytical CRM tools proposes to better know its customers by the analysis of centralized and structured data around the notion of customer, [22]

The concrete applications of analytical CRM are numerous: customer value tracking (cross-fertilization of quantitative and qualitative data), customer segmentation, analysis of cross selling opportunities and up selling (principle of additional or additional sales) analysis of the quality of service rendered to the customer, measurement of the impact of marketing campaigns [9] and improved sales and customer loyalty. [26]

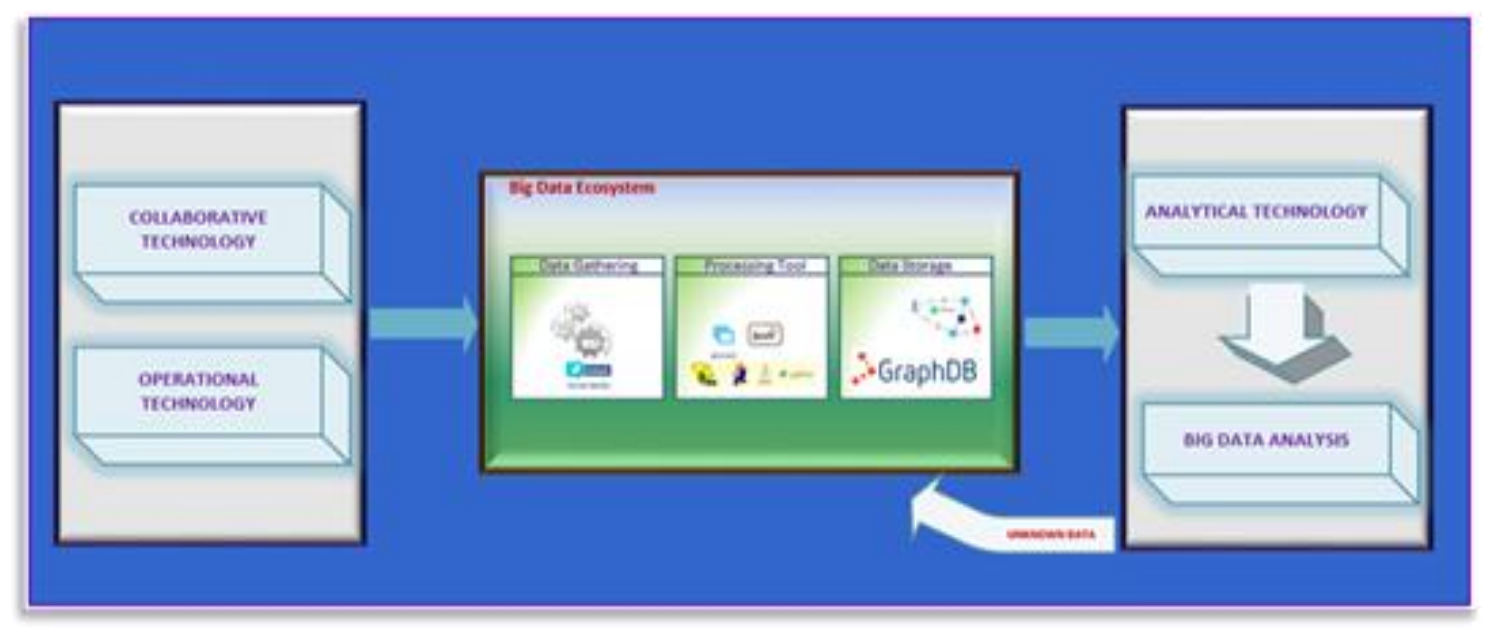

Figure 2. High Level Design for Proposed Model

\section{DesignedArchitecture}

InBased on the study of CRM systems made in the previous sections, we inherited the concepts to propose our architecture. In our model, we added a complete module as illustrated in the figure below, which represents a Big Data ecosystem which will have as main task the preparation of the data to be treated converging with other existing, and those which are in fact the results of the previous Interpretations. We propose three main sub-modules:

Real-time analysis, storage tools and processing tools. These three modules are complementary in terms of data processing (excluding the techniques and algorithms used) and in terms of real time, special mechanisms in terms of storage must be adapted [17,20]. The synchronization between these three submodules will be decisive to complete the overall process of interpretation of Big Data $5 \mathrm{~V}$. In case of separation of these three modules, we will see that the complexity can decrease by mixing the available tools (analysis, storage, treatment) such as hadoop, pentaho, Hbase, MongoDB, unlike traditional approaches, service-oriented solution introduces a service layer into the logical view of information technology, Services create an intermediate layer between business processes and applications that support their execution. Services encapsulate certain capabilities of business applications or processes. In this architecture style, integration can be done at the level of process activities and not at the level of 
business applications. Moreover, this integration is done via well-defined service interfaces that are accessible by several users.

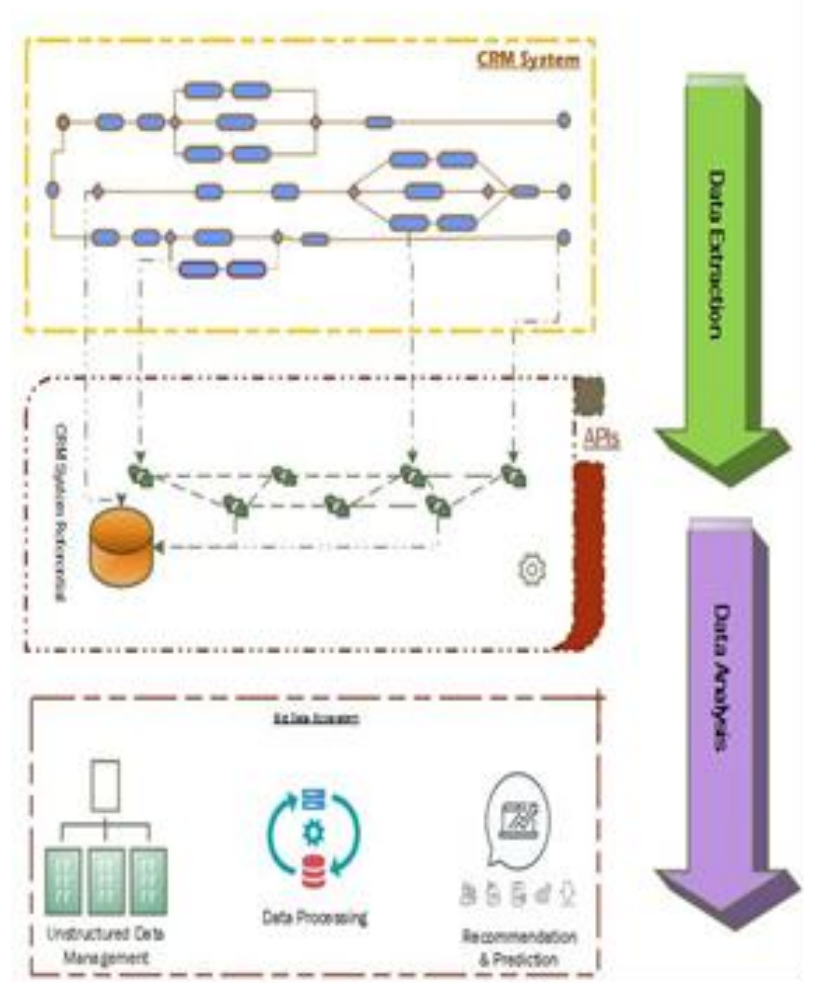

Figure 3. Deployment and implementation for proposed model

The main work is to consume the repositories of existing CRM solutions, after having determined and defined a subset that will allow to classify common elements, and to facilitate interfacing configuration with other modules of the proposed Big Data ecosystem.SOA respects the service-oriented paradigm to locate the discovered service at the logical architecture level as the primary means for building logical solutions that consist of services. These solutions form a new generation of distributed computing platforms called Service-Oriented Computing (SOC)[20]. Therefore the main objective of a company engaging in an SOA approach is the rationalization of the business. Finally, the authors in [13], specify that SOA is primarily an architectural and organizational approach: the choice of technologies and tools remains secondary. It is an architectural style that allows the company to make better use of the strategic lever that constitutes the information system becoming a true partner of the functional departments.

\section{RECOMMENDATION AND TRUST-BASED APPROACH}

\section{$\underline{\text { Recommendation: }}$}

The goal of recommendation systems is suggesting a user the items that might be of interest for him/her [27]. The ratings of the unseen/unrated items are estimated using heuristics and machine learning approaches and then the items with the highest estimation values are chosen.At their best, smart systems serve buyers and sellers alike: Consumers save the time and effort of wading through the vast possibilities of the digital marketplace, and businesses build loyalty and drive sales through differentiated experiences. 


\subsection{Challenges and Improvements:}

The expectations from a recommender system are giving good recommendations and estimations (accuracy), predicting rating of items (coverage), recommending new items (novelty), recommending different items (diversity), not strongly changing recommendations in a short time (stability), and not being affected by attacks (resistance to attacks) [25].

The main challenges of recommender system are:

Data sparsity: It is unlikely that two users rated same items many times. This makes it harder to calculate similarity.

Cold start for user: The user who has not rated sufficiently many items may suffer from not getting accurate results. This may occur since similar users to this user can not be found.

Cold start for item: The newly introduced item may suffer from not getting enough ratings, which leads to not being recommended to anyone

Attacks: There can be attacks to the recommendation system, such as copying the users whole profile and make system to think that the attacker and the user are very similar. This way an attacker can fool the system and make it suggest any item rated by attacker to the user.

We took into consideration these challenges to look for an approach that can help to enhance the recommendation systems buy using social trus and analyses how we use relationships to design the solution.

\subsection{Trust-Based recommendation}

Many social scientists are attracted to the subject of trust. Yet, to date, none of them has proposed a unanimous definition. Georg Simmel was one of the first sociologists to write about trust. According to Georg, this is one of the most important socializing forces in society. For others , [24], it is a mechanism to reduce the complexity of the social world.

The models of computational trust stand out according to the type of trust considered (local, global), their scales of confidence values (binary, gradual, probabilistic), their consideration or not of the mistrust, their strategy to propagate the confidence.

Content filtering requires the provision of semantic data on items, in addition to an analysis step to retrieve and represent them In our system, we have similar cases where products in companies do not have enough information to achieve this correlation with the customer. We opt for a hybridization in this case by increasing the properties (Figure 3 Ecosystem Big Data) thanks to unknown data (feelings of users, explicit need, competition ...). Following the global analysis of social networks and user profiles, this first analysis will give more information even in the case of a new user, and this challenge - Cold Start - is part of the elements presented in the previous section. Then, we improve our recommendation in the case where the attributes are quite sufficient, by the handling of the customers network is a sub-element of the social networks, more particularly, the modeling of the trust, as added value in our system. After applying a logistic (or linear) regressionwe add the weight of trust as an attribute by querying our local database of relationships and mapping results nodes with social network APIs to have information that responds if needed.

\subsection{Trust-Based recommandation - proposed architecture}

Our approach followed is to extend the functionality of a traditional CRM system to enable the sales force agent to choose the right products to present to customer during a visit or prospection. Our system is part of the front office tools of the company to allow interaction with the client in the sense of socialization with people in charge of cooperation and partnership (manager, purchasing department, decision makers, ...) [15]. These must create a personal space. The system, using the APIs (step "2.1" and the data extracted in step "1"), queries social networks (in our case twitter, LinkedIn or Facebook), seeks to extract filtered information focused on the business (or person in charge) in question and / or its products. We are interested in the extraction of networks of friends, tweets about the company 
(sector of activity, service or product of the company, ...). Following the data of step "1" and "2", we try to build a first graph, if the data are considered insufficient, we go to step "3".Initially, during step "3", the system gives a global view of customers' sentiments towards the elements (product, Service) of filtering used by making the sentimental analysis of the text. We can also analyze the return of social data to have the feelings of people and other companies in general towards the company in question, as a result, we will store the result of the analysis of feelings in a new attribute at the end of the step "3.1" are other key data that illustrates the hybridization by increasing attributes.

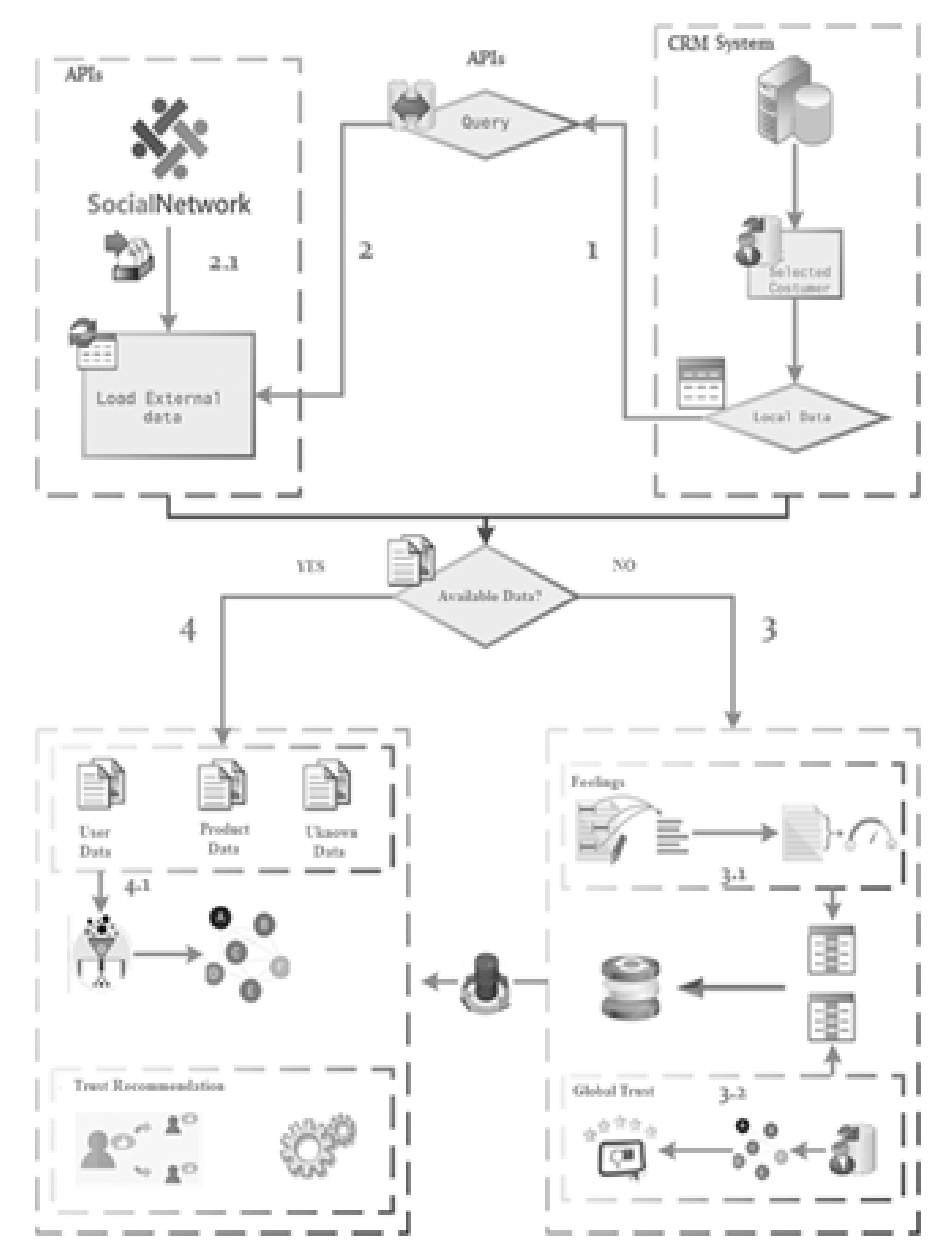

Figure 4. Trust implementation Architecture

User profiles sometimes do not contain key information for our model, which is a point of difficulty for recommendation systems in general. We chose to add attributes to the company's internal data to overcome this issue. The first piece of information is the overall trust that we can have either by calculating the trust of each user or, in the case of lack of data, we can have it following a semantic analysis of the social networks and / or the returns of the customers on an exact product.

This model is based on the architectures of major publishers, and to ensure the integration and exploitation of big data data we used the APIs to extract new knowledge. Experiments will be the subject of future work

\section{Conclusion}

The impacts of social networks are visible in many areas. These networks have come in our lives, and many of their applications will remain available for a long time, thanks to the many benefits they bring. In addition, other functions of social networks remain unexplored, and will develop further simplifying our lives. The advent of technology is transforming people's habits considerably. 
Our work presented a summary study of existing architechtures offered by known specialist industries, and a comparaison is made to clarify the model that we proposed, we added an ecosystem that is capable of integrating Big Data in order to create new added value and competitive features.

Trust between partners in a relationship results in the ability to believe that one will always act for the good of the other and will not engage in opportunistic action that may be harmful to the other. Trust relies on two elements: credibility and benevolence. The first element refers to the reliability of the partner's skills. The second is the belief that the intentions of one partner are good for the other. But, given the asymmetry of the positions of the partners involved in the relationship, trust has a good chance of being under asymmetry too, namely reciprocity.

Our research is based on models verified and can have perspectives to focus on technical faisability and technology comparaison, and consolidating strenghts of each solution and explore new data.

\section{References}

[1] Gartner Group, "CRM Success Is in Strategy and Implementation, Not Software," available at http://www.gartner.com. 2003.

[2] J. Reynolds. A Practical Guide to CRM. New York: CMP Book, 2006

[3] Intro au Social CRM : le grand-frère du Community Management, pix-geeks.com, Fabien Elharrar 2012

[4] Mercator 8ème éditionChapitre 17 le marketing relationnel, Landrevie, Lévy, Lindon pp. : 25

[5] Radcliffe , John, Eight Building Blocks of CRM: A Framework for Success, Gartner research, 2001

[6] S. RezaiianFardoie, M.A SanieeMonfared, A new design architecture for e-CRM systems (Case study: tour package choice in tourism industry), IEEE ICMIT, Proceedings of the 2008, pp.463-468

[7] Janjicek, R., CRM architecture hp, technical white paper, 2005.

[8] M Viljoen, JA Bennett, AD Berndt \& CR van Zyl, the use of technology in customer relationship management (crm), Acta Commercii 2005, pp.106-116

[9] Zhang Guozheng*, Chen Yun, Fu Chuan, A Study On The Relation Between Enterprise Competitive Advantage And Crm Based On Data Mining, International Technology And Innovation Conference, 2006, pp.1710-1714

[10] Christos Giannakis-Bompolis, Christina Boutsouki, Customer Relationship Management in the Era of Social Web and Social Customer: An Investigation of Customer Engagement in the Greek Retail Banking Sector, Procedia - Social and Behavioral Sciences, 2014, pp.67-78

[11] M.I. Kramer, ,"Comparing CRM Architectures, How the Architectures of Epiphany's, Oracle's, PeopleSoft's, SAP's and Siebel's CRM Product Suites Stack Up against Each Other, Seybold_Comparing CRMArchitetures_Report.pdf, Patricia, Seybold Group, 2003.

[12] David Puglia, Building E-CRM Architecture: Customer, Relationship Portals, 2004.

[13] E. A. Marks and M. Bell, Executive's Guide to Service-Oriented Architecture

[14] Doug Laney, 3D Data Management: Controlling Data Volume, Velocity, and Variety, Technical Report, 2001.

[15] A. DAIF, The potential and challenges of Big data: Recommendation systems next level application, IJCSI International Journal of Computer Science Issues, Vol 11, pp: 21, 2014

[16] I.A.T.Hashema, I. Yaqooba, N.B.Anuara, S. Mokhtara, A. Gania, S.U.Khanb, The rise of big data on cloud computing: review and open research issues , Inf.Syst.47(2015)98-115.

[17] M. Fazio, A. Celesti, A. Puliafito, M. Villari, Big Data Storage in the Cloud for Smart Environment Monitoring, Elsevier, pp:500-506, 2015

[18] Pietro Colombo, Elena Ferrari, Privacy aware access control for Big Data: A research roadmap, Big Data Research Accepted manuscrit, 2015. 
[19] Gema Bello-Orgaz, Jason J. Jung ,*, David Camacho, Social big data: Recent achievements and new challenges, Elsevier, pp:20,37, 2015

[20] F. El Jamiy, A. Daif, M. Azouazi, and A. Marzak, "An Effective Storage Mechanism for High Performance Computing ( HPC )," vol. 6, no. 10, pp. 186-188, 2015.

[21] F. El Jamiy, A. Daif, M. Azouazi, and A. Marzak, "An Optimized File System for High Performance Computing (HPC)," vol. 3, no. 4, pp. 3-5, 2015

[22] Mark Xu, John Walton, (2005),"Gaining customer knowledge through analytical CRM", Industrial Management \&Data Systems, Vol. 105 Iss: 7 pp. 955 - 971

[23] J. Bobadilla, F. et al. 2013, "Recommender systems survey ", Knowledge-Based Systems 46 (2013) 109-132

[24] Deutsch, M. (2006). A framework for thinking about oppression and its change. Social Justice Research19: 7-42

[25] Y. Almutairi (2019). Review Helpfulness Prediction: Survey, Periodicals of Engineering and Natural Sciences

[26] S. Selcuk (2013), Quality Management In Logistics Sector: Principles And Practice, Periodicals Of Engineering And Natural Sciences

[27] A. HIZIROĞLU (2013), A Conceptual Framework of a Cloud-Based Customer Analytics Tool for Retail SMEs, Periodicals Of Engineering And Natural Sciences 